\title{
Low risks, high public concern? the cases of persistent organic pollutants (POPs), heavy metals, and nanotech particles
}

\section{Working Paper}

\section{Author(s):}

Scholz, Roland W.; Siegrist, Michael

Publication date:

2008

Permanent link:

https://doi.org/10.3929/ethz-a-005830200

Rights / license:

In Copyright - Non-Commercial Use Permitted

Originally published in:

IED working paper 5 


\section{Low Risks, High Public Concern? The Cases of Persistent Organic Pollutants (POPs), Heavy Metals, and Nanotech Particles}

Roland W. Scholz \& Michael Siegrist 



\title{
Low Risks, High Public Concern? The Cases of Persistent Organic Pollutants (POPs), Heavy Metals, and Nanotech Particles*
}

\author{
Roland W. Scholz ${ }^{* *}$ and Michael Siegrist ${ }^{* *}$ \\ ${ }^{* *}$ Chair of Natural and Social Science Interface, ${ }^{* * *}$ Chair of Consumer Behavior \\ ETH Zurich, Institute for Environmental Decisions IED, Universitaetsstrasse 22, CH-8092 Zurich
}

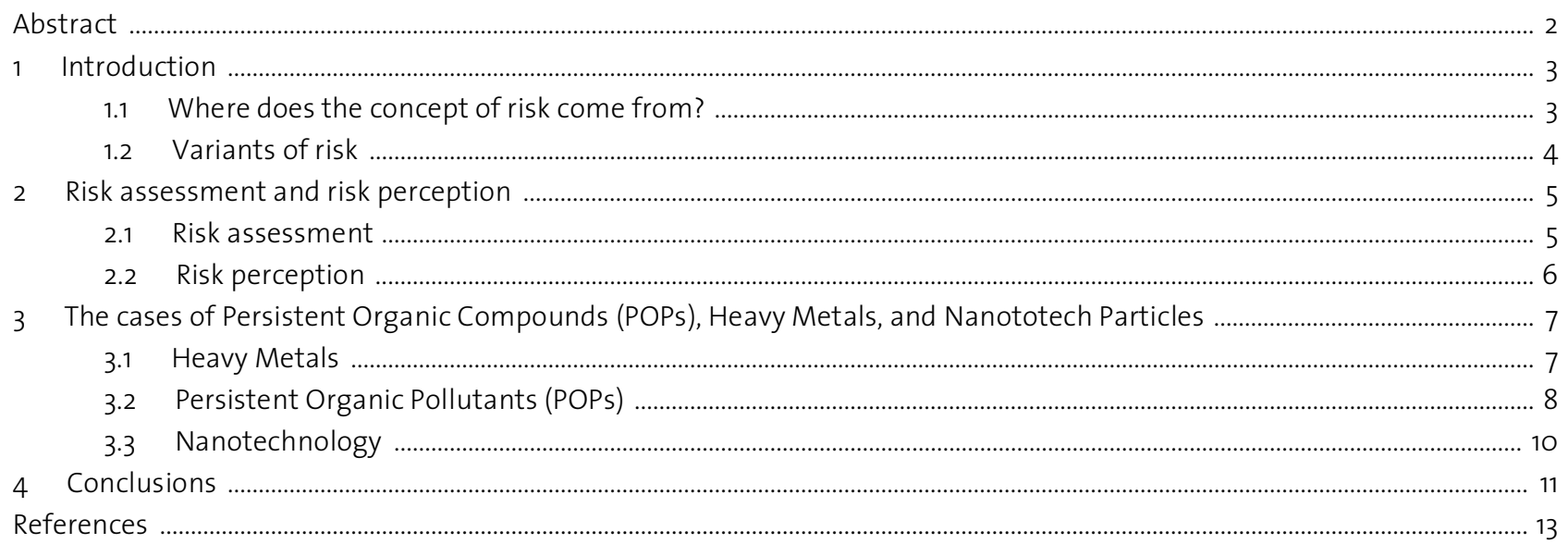




\section{Abstract}

Risk is an ancient, historic concept. It is a primitive in the sense that almost everybody has some subjective understanding of what is meant by risk. There are, however, different definitions and notions of risk. For instance, the notion of pure risk only considers negative events or losses. The term speculative risk, on the other hand, incorporates the evaluation of both benefit and harm. Furthermore, it is important to distinguish between science-based risk assessments and subjective, individual and public risk perception. Scientific risk assessment consists of well-defined procedures and methods for assessing the likelihood of future negative events. Individual and public risk perceptions are affected by what is officially stated about the effects of certain pollutants, technologies or instances. Risk assessment and risk perception are to some extent interrelated. We introduce some fundamentals of risk assessment and risk perception and report what is known about these in the significant cases of heavy metals, POPs and nanotechnology. To date, the three cases do not represent stigmatized risks, as is the case with nuclear material or genetically modified organisms. But all three cases embody significant environmental risks. We will report on possible risks and on the research examining public risk perception. 


\section{Introduction}

\subsection{Where does the concept of risk come from?}

Historically, the first pre-concepts of risk were already known by the Mesopotamians about 3,000 years before Christ (Oppenheim 1977; Mumpower, Menkes et al. 1986). It is interesting to see that the Mesopotamians had a profession of risk experts. This was a group of wise men called the Ashipu, and they were responsible for risk management. The Ashipu were elected, as they could read signs from the gods and thus were supposed to provide an excellent service of aiding in decisions to their clients. In order to assess the likelihood of positive and negative outcomes regarding different matters (e.g. of starting a war or not), they simply noted on clay disks the advantageous or disadvantageous signs associated with each matter. After recording the data, they recommended a solution, which was simply made by taking the alternative that had more positive signs.

The term risk became common in the 15th century in North Italian merchandising. Etymologically, risk refers to the Latin ricare, which originates from the Greek concept $\rho i \zeta \alpha$, which, in turn, means root as well as cliff. A Hellenistic sailor took $\rho i \zeta \alpha$ if he chose a route close to the cliffs, which increased the peril of shipwrecking but also shortened the distance traveled.

The scientific concept risk was introduced by Laplace when dealing with "the probability of the events linked to the hope but also the anxiety of tomorrow" (Laplace 1816, 1921). In this context, hope is defined as the expectation of an uncertain but likely benefit. Note that Laplace already defined risk as the product of all harms and benefits multiplied with the probability of their occurrence.

The notion of risk became accentuated with the rise of the industrial age. Harm, at that time, was merely considered opportunity costs for gaining access to the benefits tied to new technologies. Here, the simple definition of risk as the probability of loss has dominated literature and practice for a long time. In Europe, for instance, the discussions on technological risks in the 1970 s were almost exclusively characterized by definitions of risk in which only the losses were considered. These conceptions in which risk is defined as an adverse outcome, can also be denoted as pure risk. The historical context also reveals why the concept of risk was narrowed down to the probability of losses. However, as Paustenbach (1989) pointed out, the environmental and health risk assessment methodologies, which were developed in 1970, were a major change compared to what existed before. Instead of a "black and white," "yes or no" answer on the existence of hazard or peril, risk assessment provides a deliberate, mostly numerically assessment relating the judgment of the likelihood of occurrence and an valuation of the impacts of unwanted, negative outcomes when being exposed.

Today, risk assessment, risk perception, and risk management have become very important. Risk became universal in that all sciences, ranging from natural through to technical, medical, and social sciences and on to the humanities, deal with this concept. Risk - and in particular environmental risk - was given a new dimensionality with the mastering of nuclear fission (Krohn \& Weingart 1987) because the human species was able to cause damage worldwide to microcosmic systems. In principle, this phenomenon is of importance for many new technological aspects. Sociologists, such as Ulrich Beck, speak about a new age called World Risk Society (Beck 1986; Beck \& Sznaider 2006). The issue here is that some scientists and other concerned people are afraid that we cannot fully exclude new technological inventions (e.g., a specific genetic manipulation in a plant or animal, a new organic compound, or a specific nanotech particle) and that these could pose such risks for humans and for the environment that it could become a risk not tolerable for our society. 


\subsection{Variants of risk}

As we can see from the aforementioned historical examples, risk has different meanings. Therefore, we speak about a concept field of risk rather than a clear and unambiguously defined concept (such as a natural number). First, it is important to know that many scientists distinguish risk from danger (Luhmann 1993). If we use the term risk, there must be the possibility to choose between different alternatives or strategies, which may lead to different outcomes (including at least one unwanted one). This is the case with technologies or man-made chemical compounds, as society or industry can, in principle, decide whether to produce them. This is not the case with natural hazards, as the path of an asteroid does not depend on human action. If we develop technological measures against asteroids, however, the danger of an asteroid is converted into a risk.

Second, an important distinction to be made is that between pure and speculative risk. If we speak about pure risk, only the negative and unwanted outcomes of certain alternatives or strategies are considered. This is done by the traditional basic definition of the risk of a decision or technical alternatives $\left(A_{i}\right)$ as the sum of all losses that may result from negatively evaluated events $\left(u_{i}\left(E_{i, j}\right)<0\right)$ related to an alternative $\left(E_{i, j}\right)$ multiplied by the probability of occurrences $\left(p\left(E_{i, j}\right)\right)$. Formally the definition of this variant of pure risk reads:

$$
r\left(A_{i}\right)=\sum_{\text {jwith } u_{i}\left(E_{i, j}\right)<0} p_{i}\left(E_{i, j}\right) * u\left(E_{i, j}\right)
$$

This simple definition dominates the financial world or health risk assessments. Number of fatalities could be viewed as an event. In this case, the risk - say of an energy plant - would be the expected number of deaths resulting from the building, operation, and destruction of a power plant.

Another variant is speculative risk. In this concept of risk, not only the losses but also the potential benefits that may result from one alternative are incorporated in a risk judgment or risk assessment (Fishburn 1982; Brachinger \& Weber 1997). There are different definitions of risks, but an uncertain negative event is an indispensable feature of risk perception and risk assessment. We should emphasize, however, that what is considered to be a negative outcome may be influenced by the description of the problem. This has been described in prospect theory (Kahneman \& Tversky 1979; Kahneman \& Tversky 2000). 


\section{Risk assessment and risk perception}

There are various conceptualizations of risk, such as mathematically defined variants of financial risk from banks, statistically assessed health risks or simulation model based risk assessments on climate change impacts (e.g. the probability of a rise of the sea level). Many risk judgments are not based on analytic, scientific judgments, however, but rather on intuition, life experience, or holistic judgments. This holds true for experts as well as for laypersons. In the context of environmental risks, which will be discussed in this paper, we will thus distinguish between science based risk assessments and people's risk perception:

1. Risk assessment procedures are evaluations of the likelihood of diverse future events focusing on, or at least including, the negative, unwanted events. Risk assessment is based on certain transparent, well-defined procedures and methods and includes both the description of the unwanted events and a characterization of the uncertainties inherent in the process of inferring risks. Risk assessment is essentially a modeling approach for evaluating risks.

2. Risk perception is based on individual experience and the mental processing of consequences of certain actions or events.

Risk management should be considered a different activity from risk assessment. By risk management we understand the process of "evaluating alternative regulatory actions and selecting among them. Risk management, which is carried out by regulatory agencies under various legislative mandates, is an agency decision-making process that entails considerations of political, social, economic, and engineering information ..." (NAS 1987). As this historical example shows, risk management includes decision making. We will not deal with risk management but focus instead on the essentials of risk assessment and risk perception for environmental risks.

\subsection{Risk assessment}

In principle, risk assessment includes the following stages (compare e.g. Paustenbach ,1989):

(a) Defining the risk situation: This includes the definition of the variables of the underlying risk assessment. The possible hazard has to be identified. This can be a toxic element (e.g., DDT) or a certain application of a technology (e.g. genetically modified crops). Furthermore, the safeguard object (e.g., fish, birds, humans, biodiversity etc.) and the system boundaries (e.g. a family, village, nation etc.) have to be defined.

(b) The negative effects have to be defined: Different aspects can be considered a negative effect. If we look at potential negative effects of airborne heavy metals, for example, we have to define whether we are interested in the acute or the chronic effect and which safeguard object we focus on (e.g. the gastrointestinal system, kidney, liver etc.; on psychological effects, or on general health). It is apparent that the assessment of an effect can be done by different technical or medical procedures.

(c) Assessing the dose-response relationship. This assessment deals with the relation between the dose (e.g. concentration or absolute load) of an agent (e.g. toxic chemical) received or administered and the consecutive incidence of an adverse health effect or negative impact on the safeguard object. Assumptions about the relationship must be made (e.g., linear, non-linear, threshold), and these assumptions influence risk assessments.

(d) Assessing the exposure. This step includes the measuring or the estimating of the intensity, frequency, and duration of human, animal, plant, ecosystem etc. due to the exposure to a chemical compound (or-technical speakingto an alternative $A_{i}$ ). 
(e) Characterizing the risk. This step includes the estimation of the frequency of a negative effect (e.g. a health effect) under the various conditions of exposure described and with respect to the safeguard object of interest.

If we look at the history of environmental risk assessment, we can trace back a long history, starting from Agricola's (1565) study on occupational risks in mining and ending with the Harvard industrial hygiene program, of identifying which diseases are due to exposure at the workplace. According to Paustenbach (1989), what we call risk assessment started around 1930. We can discriminate between different risk assessment methods, which are based on different scientific roots and data and acknowledge the uncertainties and the issues of the above points (a) to (e) in a different way. In particular, we can distinguish between

- Epidemiological studies: These studies investigate the distribution of diseases within a population and possible factors causing them. Often these studies are post hoc, and historical data are used: A critical issue is that it is extremely difficult to identify the specifics of the contextual factors and the precise conditions of exposure (Rothman \& Greenland 1998)

- Animal experiments: As it is mostly ethically not feasible to expose humans to environmental toxicants, certain animals serve as "model observations" (animal bioassays). A critical issue is in what way the doseresponse relationships observed in animals can be used to make statements for human species; furthermore, the doses are often unrealistic high, and the question is what conclusions can be made for humans.

Further, there are other methods such as simulation based on literature data, low-dose human experiments with volunteers or expert judgments for cases.

\subsection{Risk perception}

By risk perception of an individual, we understand all mental, emotional (affective) and psychophysical processes (e.g. the change of hormone level), which are linked to risk in a risk situation. In this context, we consider risk as a primitive (Sokolowska 2006) or as cognitions and emotions which are saliently associated with the semantics of risk (Scholz \& Tietje 2002, p. 181).
Risk perception is not only a matter of numbers. According to the seminal work of Slovic, Fischhoff \& Lichtenstein (1979), risk has a kind of personality. Obviously, decision makers are not only taking the statistical (actuarial) data into account, but are rather strongly influenced by their own interpretation of the situational characteristics. Judgments of riskiness rely on many other aspects than statistical frequencies. In studies examining risk perception, participants assess, for example, how dreadful the hazards are, whether the risks are known to science, and whether people have control over their exposure to the hazard (Slovic 1987). Results of this research suggest that qualitative dimensions are more important than actual fatalities for lay people's risk perception. Lay people tend, for example, to assess commercial aviation as more dreadful than cars. The reason for this perception is that, in the case of aviation, a large number of people can be killed in an accident. Car accidents are more common, of course, but few people are killed in each accident. Results suggest, therefore, that, as in this example, the mean value of fatalities is not important for lay people's risk perception, but rather the maximum of possible fatalities. The fact that people perceive low-probability, high-damage events as dreadful may have undesirable consequences. Americans reacted to the terrorist attacks on September 11, 2001 by reducing their air travel. Many people decided not to fly but rather to drive to their destinations. Flying would have been safer than driving a car, however. Gigerenzer (2006) estimated that 1,500 Americans died on the road attempting to avoid the unlikely event of being killed in an airplane by terrorists.

The psychometric paradigm, described above, was the first approach for examining the research question of why the public perceives various hazards differently (Slovic 1987). Newer approaches for explaining people's risk perception are the affect heuristic (Finucane, Alhakami et al. 2000) and implicit attitudes (Siegrist, Keller \& Cousin 2006). The affect heuristic assumes that people have positive and negative feelings related to a hazard. The overall affective impression that is associated with an object determines people's risk perception. The affect heuristic has been used to explain why people believe that a risky event is associated with low levels of benefits, and that a beneficial hazard tends to be perceived as a hazard that poses little risk (Finucane, Alhakami et al. 2000) 


\section{The cases of Persistent Organic Compounds (POPs), Heavy Metals, and Nanototech Particles}

\subsection{Heavy Metals}

From the periodic table, 80 out of 105 elements are considered metals. About thirty of them are considered toxic, and 23 of them are heavy metals (Steven 2007). Lead, cadmium, mercury, arsenic, but also aluminums (as dust or as additives in water) are harmful. These metals are well explored, as through human occupational exposure significant poisonings became visible very early. Hippocrates described a man and the impact on his health due to smelting arsenic and mercury, called metal fume fever, which was known in ancient Greece. The dissemination of heavy metals was linked to most industrial processes and was a characteristic of the industrial age, in particular the heavy metal in dustry and allied combustion processes. Various measures were used in order to have the use of leaded gas phased out, such as filtering techniques, as well as documented studies on the environmental and health damages caused by lead. As a result, in the U.S., the Clean Air Act for road vehicles was passed in 1996.

There is a multitude of human health impacts of heavy metals ranging from the ingesting organs (lung, gastrointestinal system, etc.), through organs (such as kidney, liver, etc.) and the central and peripheral nerve system, to the bones. One should note, however, that many nutrients and all environmental settings include heavy metals, which are - in general - part of the universal material flow. Therefore, one has to discriminate between a basic natural exposure and additional exposure to humans made by contaminated soil, air and subsequently increased loads. Thus, an environmental risk assessment requires not only assessing the (a) risk situation, (b) the existence of negative effects and (c) the dose-response relationship, but also (d) the multiple exposure. This is essential as some of these metals, such as Cadmium, come from smoking or natural sources (such as ingesting something containing heavy metal soil dust; Scholz, May et al. 1991). It should be emphasized that both assessing the exact exposure, i.e. the uptake from different sources, as well as the doseresponse functions, are difficult processes that include the modeling of uncertainties in the data and in the knowledge by means of probabilistic models (Wallsten \& Whitfield 1986; Scholz, May et al. 1992; Nothbaum 1997; Scholz, Heitzer et al. 1997; Cullen \& Frey 1999). If a certain uptake has been (probabilistically) assessed, the (probabilistic) dose-response relationships can often only be quantitatively specified for certain physiological parameters, which are responsible for certain physical or mental harm. So, characterizing the effects of exposure to environmental contamination asks for expert-based judgments (e) and thus includes uncertainty.

Several studies have investigated people's risk perception of heavy metals (Krogmann, Gibson et al. 2001; Weber, Scholz et al. 2001; Grasmück \& Scholz 2005; Scholz \& Schnabel 2006). The study of Weber, Scholz et al. (2001) included people who actually lived on contaminated soil and compared their risk judgments with people not living on a contaminated site. One should note that the maximum contamination level is typically rather low (i.e. investigated sites in the target area in Switzerland were rather low, in the contaminated area e.g. below $<5$ ppm (d).

A factor analysis showed that the factors dread, control, and catastrophic potential were relevant to the perception and evaluation of low-dose environmental risks such as the contamination of the investigated area, whereas the catastrophic potential was realistically judged as low. 
A cluster analysis showed that people perceived the heavy metal soil contamination as being similar to that of oil contamination, ozone layer, preservatives and genetic technology. It was perceived indifferently with regard to dread.

Sustainability or precautionary issues, such as the prevention of harm for future generations, were highly correlated with the acceptance of the use of bioremediation methods in people's residential areas.

The study of Grasmück \& Scholz (2005) compared people on more- and less-contaminated sites. Both groups judged the risk for themselves similarly. Quite surprisingly, the low-exposure group, when compared to the high-exposure group, judged perceived risk for other affected people living in their community to be higher. Unfortunately, the survey does not reveal whether this is an impact of illusionary control or whether this is an impact of (believed) behavioral change of the respondents.

A main finding was that risk perception was not so much determined by actual exposure to heavy metals but to emotional concerns. So, the emotional and highly concerned persons had a higher desire for additional knowledge, provided lower scores in self-estimated knowledge, and showed lower risk acceptance. Factually, the question addressing knowledge about contaminated soil did not differ between the people with high and low emotional concern.

Judgments on the need for decontamination are determined by risk perception, and not by a commitment to sustainability. The desire for additional information is not affected by missing knowledge but is affected by emotional concerns.

\subsection{Persistent Organic Pollutants (POPs)}

The environmental decision-making community is now facing the adverse health and ecological effects of POPs. The situation regarding POPs is much more complex than with heavy metals. In the domain of the European Union alone there are 100,000 registered industrial manufactured chemicals and most of these are in daily use (EINECS, Allanou 2007). Critical POPS are often chlorine compounds. Well-known examples are DDT, PCDDs (polychlorinated dibenzo-pdioxines) PCDFs, (polychlorinated dibenzofurans), lindane (beta $\mathrm{HCH}$ ) or PCB (coplanar polychlorinated biphenyls). In addition, carcinogenic polycyclic hydrocarbons (PAHs) are considered POPs. POPs are caused by many human activities including combustion for energy production and transportation, industrial processes, and agricultural uses of pesticides. POPs can be found in all environmental settings and are accumulated particularly in fat tissues.

As the attribute persistent indicates, POPs have a very long lifetime and are characterized by long distance travel in water and (due to their semi-volatility) in the air. This allows for long-range transportation and multiple environmental interactions. Because they travel long distances and cross local regulatory boundaries, POPs cannot be regarded as a local problem. One can say that the "scientific or regulatory community has not adequately addressed human exposure to POPs through multiregional, multimedia exposure scenarios" (Bennet, McKone, \& Kastenberg 2002). For instance, to date, an effective and sustainable global strategy against unseen contamination of aquatic environments barely exists (Schwarzenbach, Escher et al. 2006).

Historically, organochlorine insecticides and the food chain were the primary sources of human uptake. "It is now clear that the group of chemicals included in the term "persistent organic pollutants" generally are present in humans as a result of their presence in diet. More than 90 percent of the intake of these 15 to 50 chemicals occurs through ingestion of fish, meat, and dairy products" ((Fries 2002), p. 890). A strong dose-response relationship between serum concentration of POPs and diabetes indicates one of the health effects (Lee, Lee et al. 2006). 




Figure 1: $\quad$ The location of chemical risks such as Chemical fertilizers or Pesticides that are related to POPs (Data from Siegrist, Keller \& Kiers, 2005 were used for this figure).

Though there have been sophisticated, so-called 'multicompartment models' (Hertwich, Pease, \& McKone 1998; Lee, Lee et al. 2006), from the perspective of environmental risk assessment the issue regarding POPs is more difficult than with heavy metals. First, we have to acknowledge the magnitude of anthropogenic fluxes of synthetic chemical production of 300 million tons per year, which is huge compared with the 0.4 million tons of average oil spill (in the time frame of 1980-2000; (FAO 2006; Schwarzenbach, Escher et al. 2006)). We would like to mention that due to the complexity of ecosystems, the ubiquity of organic chemical cocktails, and due to biological processes, which start at bacterial and micro level, including enzymatic and surface related reactions (Schwarzenbach, Escher et al. 2006), the risk assessment approach sketched above (separating exposure and effects) can come to its limits if systemic risks are considered.

\begin{abstract}
The mutual interaction of thousands of chemicals in the environment with millions of biological species will ultimately determine whether a given pollutant (mixture) leads to marginal or catastrophic ecological consequences. ((Schwarzenbach, Escher et al. 2006), p. 1075)
\end{abstract}

There have been many studies investigating the risk perception of chemicals (Mertz, Slovic, \& Purchase 1998; Tucker \& Napier 1998; Beehler, McGuinness, \& Vena 2001; Slovic 2001; Tucker \& Napier 2001) but nonethat focused on POPs. However, DDT and chlorides were sometimes included in the so-called 'psychometric approach.' Results consistently show that these chemicals are not at the extremes of the subjective factors such as dread and unknown (Slovic 1987; Siegrist, Keller \& Kiers, 2005), though lack of knowledge seems to be essential (see Figure 1).

Also, other studies show that sport fishers (Beehler, McGuinness, \& Vena 2001) or farmers (Tucker \& Napier 2001), who are more exposed to POPs than the average person, do not show considerable concern. There are, however, differences of chemical risk judgments between the senior managers of the chemical industry and the public. Those who benefit, i.e. the senior managers, show less concern than the public (Mertz, Slovic, \& Purchase 1998). This difference might be due to the fact that the managers refer to the concept of speculative risk and incorporate the benefits (both for themselves and for the public) that emerge from producing and applying the POPs. But toxicolologists' intuitive judgments of chemical risks are alsolower than those of laypersons (Slovic, Malmfors et al. 1995).

These studies might reveal that value judgments and other issues such as social justice (who benefits from a risk) are essential factors of risk perception. This also holds true for the environmentalist movement. One should note that the cradle of the environmentalist movement is Rachel Carson's book 'Silent Spring' (Carson, 1962). The book describes how the subtle but dramatic impacts of POPs were identified, and the term biocide was first coined there. If symbolic values are included, then public risk judgments are seriously affected. 


\subsection{Nanotechnology}

Nanotechnology is perceived as one of the key technologies of the $21^{\text {st }}$ century. This technology will generate new products with various benefits. At present, we do not fully understand potential health risks or environmental risks from engineered nanoparticles (Morgan 2005). Since nanotechnology allows the introduction of new properties to materials, it could potentially lead to huge benefits. The use of such materials may also mean that these products may be associated with some risks (Pusztai \& Bardocz 2006). Recent studies suggest that at least some nanomaterials may be problematic for humans or for the environment (Oberdörster, Oberdörster, \& Oberdörster 2005). Results of these risk assessment studies do not presently allowthe definitive quantification of the risks to humans and the environment associated with nanotechnology. In addition to these risks, the development of nanotechnology faces risks in terms of unintended economic and societal impacts. Various stakeholders seem to agree that public perception and public acceptance of nanotechnology will be crucial for the realization of technological advances (Royal Society and Royal Academy of Engineering 2004). It is remarkable that the Royal Society addressed both risk assessment issues and risk perception issues. It is hoped that in addressing public perception at an early stage that acceptance problems, which were observed for genetically modified foods in Europe, can be avoided.

Recent surveys suggest that the public does not know a great deal about nanotechnology (Cobb \& Macoubrie 2004). In a recent study, we examined how lay people perceived various nanotechnology applications (Siegrist, Keller et al. 2007). In order to assess public perception of this new technology, participants have to be informed about possible risks and possible benefits associated with nanotechnology. Based on this information, participants were asked to evaluate various nanotechnology applications on several qualitative dimensions. Results suggested that perceived dreadfulness of applications and trust in governmental agencies are important factors for lay peo- ple's risk perception. It should be added that similar results were observed for both experts and laypeople, but the latter perceived greater risks than the former. Results of this study indicate that public concerns about nanotechnology may diminish if measures are taken to enhance public trust in governmental agencies regulating nanotechnology.

Nanotechnology is increasingly being employed in the areas of food production and food packaging (Sanguansri \& Augustin 2006). Food and nutrition products containing nanoscale additives are already commercially available. It is expected that nanotechnology will become increasingly important in the near future. The public showed low levels for stated willingness to buy nanotechnology foods or food with nanotechnology packaging (Siegrist, Cousin et al. 2007). Furthermore, results of this study indicate that nanotechnology packaging is perceived as being more beneficial than nanotechnology foods. As suggested by the affect heuristic (Slovic, Finucane et al. 2002), affect had an impact on perceived benefits and perceived risks. In the absence of sufficient knowledge, trust and affect are important heuristics that guide our decisions.

Public discussions in the fields of gene technology and nuclear power show that public perception may have a strong impact on the development, funding and acceptance of a technology. In the field of nanotechnology there seems to be some agreement, that, in addition to risk assessments, there should also be concern assessments (Renn \& Roco 2006). In our view, nanotechnology is a good example of a new technology for which technological assessment and examination of public concerns started at an early stage (Royal Society and Royal Academy of Engineering 2004). It is hoped that addressing public concerns during the development of new products may facilitate public acceptance. It remains to be seen whether the mistakes made in the GM debate can be avoided and whether the introduction of nanotechnology will be more sustainable. 


\section{Conclusions}

We have introduced different concepts of risk (pure and speculative), introduced the fundamentals of risk assessment and risk perception, and analyzed the state of the art of research on three cases. These cases differ with respect to their history, the knowledge gained on negative impacts on human and environmental health, and on other issues. The impact of heavy metals on health has been known for a long time. For some metals, such as mercury, cadmium or lead, a great deal of data about dose-response is available. Thus, the classical procedures of risk assessment by quantitatively relating the exposure of a safeguard object to the incidence probability of a certain damaging effect can be ideally applied to this case. This is different for POPs, for which the interaction with other chemical compounds (i.e. the impact of unknown cocktails) and unknown effects on the micro-level appear to be more important. Nanotechnology is an issue of the $21^{\text {st }}$ century and though there is a consensus about the uncertainty of possible risks, no comprehensive risk assessment procedure has yet been developed for these particles. From an environmental and natural science point of view, all these cases deserve high attention with respect to national and international risk management. As history has shown, particularly with regard to heavy metal contamination, there have been large environmental risks and subsequent financial losses emerging from these types of chemicals and particles.

From a psychological perspective, these cases have something in common. They do not belong to the hazards stigmatized by the public, such as nuclear technologies or genetically modified organisms. However, when POPs and nanotech particles (and also heavy metals in principle) are seen in the context of food or as harmful to highly valued issues such as prized species (e.g. eagles), which also have a symbolic value, these issues might change.

Risk perceptions differ across countries and cultures. Different stakeholders provide different risk judgments. In the domain of nanotechnology, laypeople perceive less risk than experts (Siegrist, Keller et al. 2007). As we have ar- gued, one reason for the confusion among stakeholders can be seen in that they utilize different concepts of risk. For instance, some may apply the concept of speculative risk, which provides an integrated view on the benefits and the negative consequences. Others may only focus on pure risks, which combine the evaluation of negative events and their probability. We should note that the application of different concepts of risks by different stakeholders in different situations is a well-known issue. For instance, concerned people under stress (e.g. when worrying about their own new-born child) tend to focus their risk judgment only on the greatest imaginable damage (e.g. that their own child may die). In contrast, people from national environmental protection agencies may think about risks in statistical terms (e.g. considering the chance that the child may die [for instance 1: 100,000]) as negligibly small.

Looking at risk assessment and at risk perception, we recommend that both should be considered from a realist stance. The biophysical effects as well as what people think are both real. The natural scientists' assessment and the perception of the public each have their own rationale. Both can be more or less appropriate, though for different reasons. Based on this statement, we think that it is important to appropriately relate risk assessments and risk perception at an early stage of technological developments. This, in particular, holds true for nanotechnology, and to some extent for POPs, as they incorporate the risk of becoming stigmatized while posing some significant risk with respect to health and ecosystems.

Clearly, risk perception should not replace risk assessment. However, as safeguard objects and risk judgments include values, lay people's risk perception should be considered as one of the factors that determines what research questions should be primarily addressed. Thus, the case studies presented demonstrate that risk assessment is not only an issue of pure natural science but also an issue of risk perception as a purely psychological or sociological matter. Both issues ask to be appropriately related. 


\section{References}

Agricola, G. (1565). De re metallica libri XII (translated by H. C. Hoover and L. H. Hoover). New York: Dover.

Allanou, R. (2007). EINECS, European Inventory of Existing Commercial Chemical Substances. Retrieved 2007-1020, from EU, European Union: http://ecb.jrc.it/esis/inde x.php?PGM=ein

Beck, U. (1986). Risikogesellschaft. Auf dem Weg in einer andere Moderne. Frankfurt: Suhrkamp.

Beck, U., \& Sznaider, N. (2006). Unpacking cosmopolitanism for the social sciences: a research agenda. British Journal of Sociology, 57(1), 1-23.

Beehler, G. P., McGuinness, B. M., \& Vena, J. E. (2001). Polluted fish, sources of knowledge, and the perception of risk: Contextualizing African American anglers' sport fishing practices. Human Organization, 60(3), 288-297.

Bennet, D. H., McKone T. E., \& Kastenberg, W. E. (2002). Characteristic time, characteristic travel distance, and population-based potential dose in a multimedia environment: a case study. In D. J. Paustenbach (Ed.), Human and ecological risk assessment. Theory and practice (pp. 619-643). New York: Wiley.

Brachinger, H. W., \& Weber, M. (1997). Risk as a primitive: a survey of measures of perceived risk. Operations Research-Spectrum, 19(4), 235-294.

Carson, R. (1962). Silent spring: Houghton Mifflin.

Cobb, M. D., \& Macoubrie, J. (2004). Public perceptions about nanotechnology: Risks, benefits and trust. Journal of Nanoparticle Research, 6, 395-405.

Cullen, H., \& Frey, C. (1999). Probabilistic techniques in assessing exposure assessmeng. A handbook dealing with variability and uncertainty in models and inputs. New York: Plenum.
FAO (2006). Statistical database, http://faostat.fao.org. Rome: Food and Agriculture Organization of the United Nations.

Finucane, M. L., Alhakami, A., Slovic, P., \& Johnson, S. M. (2000). The affect heuristic in judgments of risks and benefits. Journal of Behavioral Decision Making, 13, 1-17.

Fishburn, P. C. (1982). The foundations of expected utility. Dordrecht: Reidel.

Fries, G. F. (2002). Transport of persistent organic pollutants to animal products: fundamental principles and application to health risk assessmengt. In D. J. Paustenbach (Ed.), Human and ecological risk assessment. Theory and practice (pp. 873-894). New York: Wiley.

Gigerenzer, G. (2006). Out of the frying pan into the fire: Behavioral reactions to terrorist attacks. Risk Analysis, 26, 347-351.

Grasmück, D., \& Scholz, R. W. (2005). Risk perception of heavy metal soil contamination by high-exposed and low-exposed inhabitants: The role of knowledge and emotional concerns. Risk Analysis, 25(3), 611-622.

Hertwich, E. G., Pease, W. S., \& McKone, T. E. (1998). Evaluating toxic impact assessment methods: What works best? Environmental Science \& Technology, 32(5), 138A144A.

Kahneman, D., \& Tversky, A. (1979). Prospect theory: an analysis of decision under risk. Econometrica, 47, 263291.

Kahneman, D., \& Tversky, A. (2000). Choices, Values, and Frames. Cambridge: Cambridge University Press.

Krogmann, U., Gibson, V., \& Chess, C. (2001). Land application of sewage sludge: perceptions of New Jersey vegetable farmers. Waste Management \& Research, 19(2), 115-125. 
Krohn, W., \& Weingart, P. (1987). Nuclear-power as a social experiment - European political fall out from the Chernobyl meltdown. Science Technolog \& Human Values, $12(2), 52-58$.

Laplace, P.-S. (1816, 1921). Essai philosophique sur les probabilités [Philosophical essay on probabilties]. Paris: Gauthier-Villars.

Lee, D. H., Lee, I. K., Song, K., Steffes, M., Toscano, W., Baker, B. A., et al. (2006). A strong dose-response relation between serum concentrations of persistent organic pollutants and diabetes - Results from the National Health and Examination Survey 1999-2002. Diabetes Care, 29(7), 1638-1644.

Luhmann, N. (1993). Risiko und Gefahr. In W. Krohn \& G. Krücken (Eds.), Riskante Technologien: Reflexion und Regulation (pp. 138-185). Frankfurt a. M.: Suhrkamp.

Mertz, C. K., Slovic, P., \& Purchase, I. F. H. (1998). Judgments of chemical risks: Comparisons among senior managers, toxicologists, and the public. Risk Analysis, 18(4), 391-404.

Morgan, K. (2005). Development of a preliminary framework for informing the risk analysis and risk management of nanoparticles. Risk Analysis, 25, 1621-1635.

Mumpower, J., Menkes, J., \& Covello, T. (Eds.). (1986). Risk evaluation and management. New York, NY: Plenum.

National Academies of Sciences NAS (1987). Pharmacokinetics and risk assessment. In NAS (Ed.), Drinking water and health. Vol. 8. Washington DC: NAS.

Nothbaum, N. (1997). Experten-Entscheidung unter Unsicherheit: Kognitive Didaktik und situative Rahmung bei der Erhebung von Verteilungswissen [Expert decisions under uncertainty: Cognitive didactics and situative framing in the determination of distributive knowledge]. Frankfurt am Main: Lang.

Oberdörster, G., Oberdörster, E., \& Oberdörster, J. (2005). Nanotoxicology: An emerging discipline evolving from studies of ultrafine particles. Environmental Health Perspectives, 113, 823-839.
Oppenheim, L. (1977). Ancient mesopotamia. Chicago, IL: University of Chicago Press.

Paustenbach, D. J. (1989). A survey of health risk assessment. In D. J. Paustenbach (Ed.), The risk assessment of environmental and human health hazards: a textbook of case studies (pp. 27-124). New York: Wiley.

Pusztai, A., \& Bardocz, S. (2006). The future of nanotechnology in food science and nutrition: Can science predict its safety? In G. Hunt \& M. D. Mehta (Eds.), Nanotechnology: Risk, ethics and law (pp. 167-179). London: Earthscan.

Renn, O., \& Roco, M. C. (2006). Nanotechnology and the need for risk governance. Journal of Nanoparticle Research, 8, 153-191.

Rothman, K. J., \& Greenland, S. (1998). Modern epidemology (2nd ed.). Philadelphia: Lippincott, Williams \& Wilkens.

Royal Society and Royal Academy of Engineering (2004). Nanoscience and nanotechnologies: Opportunities and uncertainties. London: Royal Society.

Sanguansri, P., \& Augustin, M. A. (2006). Nanoscale materials development - a food industry perspective. Trends in Food Science \& Technology, 17, 547-556.

Scholz, R. W., Heitzer, A., May, T. W., Nothbaum, N., Stünzi, J., \& Tietje, O. (1997). Datenqualität und Risikoanalysen: Das Risikohandlungsmodell zur Altlastenbearbeitung [Data quality and risk analyses. The risk action model of soil remediation]. In S. Schulte-Hostede, R. Freitag, A. Kettrup \& W. Fresenius (Eds.), Altlastenbewertung. Datenanalyse und Gefahrenbewertung [Evaluation of soil remediation cases: analysis of data and evaluation of risks] (pp. 1-29). Landsberg: Ecomed-Verlag.

Scholz, R. W., May, T. W., Hefer, B., \& Nothbaum, N. (1991). Die Anwendung des Donator-Akzeptor-Modells am Beispiel Blei für den Pfad "Boden-Mensch". [An application of the donator-acceptator model for the lead path "soil-humans"]. In E. Bütow (Ed.), Ableitung von Sanierungswerten für kontaminierte Böden [Determination of remediation standards for contaminated soils] (pp. 55-98). Berlin: Schmidt. 
Scholz, R. W., May, T. W., Nothbaum, N., Hefer, l., \& Lühr, H. P. (1992). Induktivstochastische Risikoabschätzung mit dem Donator-Akzeptor-Modell am Beispiel der Gesundheitsbelastung durch cadmiumbelastete Weizenackerböden. [An inductive and stochastic risk evaluation with the donator-acceptor model: the example of the health consequences of cadmium contaminated soils of wheat fields]. In W. van Eimeren, K. Ueberla \& K. Ulm (Eds.), Gesundheit und Umwelt (pp. 57-61). Berlin: Springer.

Scholz, R. W., \& Schnabel, U. (2006). Decision making under uncertainty in case of soil remediation. Journal of Environmental Management, 80(2), 132-147.

Scholz, R. W., \& Tietje, O. (2002). Embedded Case Study Methods: Integrating quantitative and qualitative Knowledge. Thousand Oaks: Thousand Oaks: Sage.

Schwarzenbach, R. P., Escher, B. I., Fenner, K., Hofstetter, T. B., Johnson, C. A., von Gunten, U., et al. (2006). The challenge of micropollutants in aquatic systems. Science, 313(5790), 1072-1077.

Siegrist, M., Cousin, M.-E., Kastenholz, H., \& Wiek, A. (2007). Public acceptance of nanotechnology foods and food packaging: The influence of affect and trust. Appetite, 459-466.

Siegrist, M., Keller, C., \& Cousin, M.-E. (2006). Implicit attitudes toward nuclear power and mobile phone base stations: Support for the affect heuristic. Risk Analysis, 26, 1021-1029.

Siegrist, M., Keller, C., Kastenholz, H., Frey, S., \& Wiek, A. (2007). Laypeople's and experts' perception of nanotechnology hazards. Risk Analysis, 27, 59-69.

Siegrist, M., Keller, C. \& Kiers, H. A. L. (2005). A new look at the psychometric paradigm of perception of hazards. Risk Analysis, 25, 211-222.

Slovic, P. (1987). Perception of risk. Science, 236, 280-285.
Slovic, P. (2001). The risk game (Reprinted from 'The risk game'). Journal of Hazardous Materials, 86(1-3), 17-24.

Slovic, P., Finucane, M., Peters, E., \& MacGregor, D. G. (2002). The affect heuristic. In T. Gilovich, D. Griffin \& D. Kahneman (Eds.), Heuristics and biases: The psychology of intuitive judgment (pp. 397-420). Cambridge: Cambridge University Press.

Slovic, P., Fischhoff, B., \& Lichtenstein, S. (1979). Rating the risks. Environment, 21, 14-20; 36-39.

Slovic, P., Malmfors, T., Krewski, D., Mertz, C. K., Neil, N., \& Bartlett, S. (1995). Intuitive toxicology .2. Expert and lay judgments of chemical risks in Canada. Risk Analysis, 15(6), 661-675.

Sokolowska, J. (2006). Risk perception and acceptance One process or two? The impact of aspirations on perceived risk and preferences. Experimental Psychology, 53(4), 247-259.

Steven, M. (2007). Toxicity, Lead. Retrieved 2007.10.17, from www.eMedicine.com: http://www.emedicine.com/em erg/topic293.htm

Tucker, M., \& Napier, T. L. (1998). Perceptions of risk associated with use of farm chemicals: Implications for conservation initiatives. Environmental Management, 22(4), 575-587.

Tucker, M., \& Napier, T. L. (2001). Determinants of perceived agricultural chemical risk in three watersheds in the Midwestern United States. Journal of Rural Studies, 17(2), 219-233.

Wallsten, T. S., \& Whitfield, R. G. (1986). Assessing the risks to young children of three effects associated with elevated blood-lead levels. Argonne, IL: Argonne National Laboratory.

Weber, O., Scholz, R. W., Bühlmann, R., \& Grasmück, D. (2001). Risk Perception of Heavy Metal Soil Contamination and Attitudes to Decontamination Strategies. Risk Analysis, 27(5), 967-977. 


TH Zurich

Institute for Environmental Decisions IED

WEH G

$\mathrm{CH}-8092$ Zurich

SWITZERLAND

Phone +41446324718

Fax +41446321042

URL http://www.ied.ethz.ch 